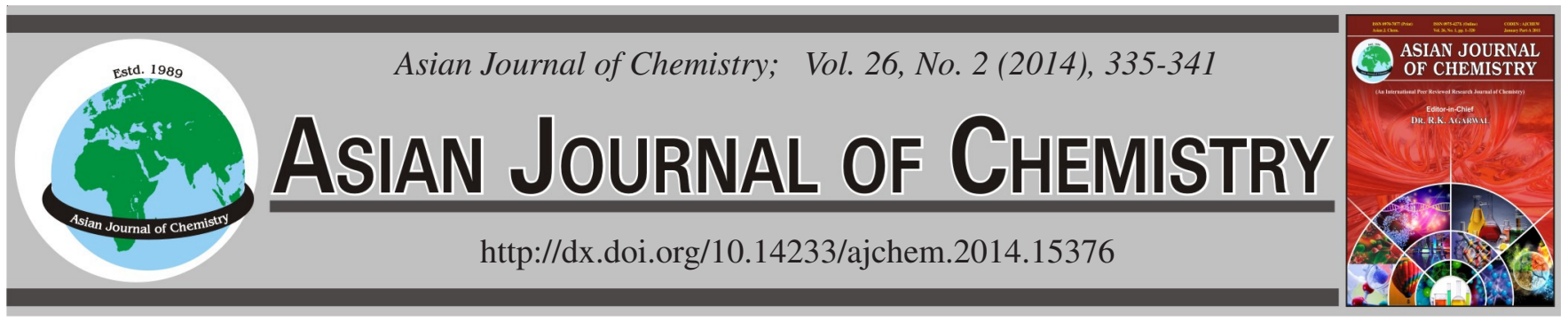

\title{
Application of LC-MS/MS Method for Evaluating Rosuvastatin Affinity with OATP1B1 and OATP2B1 in vitro
}

\author{
Zhi-Yu Zhang ${ }^{1,2}$, Quan-Sheng Li ${ }^{2}$, Duan-Yun Si ${ }^{2}$, Xiu-Lin YI ${ }^{2, *}$ and Chang-XIAo Liu ${ }^{2, *}$
}

${ }^{1}$ School of Chemical Engineering and Technology, Tianjin University, Tianjin 300072, P.R. China

${ }^{2}$ State Key Laboratory of Drug Delivery Technology and Pharmacokinetics, Tianjin Institute of Pharmaceutical Research, Tianjin 300193 , P.R. China

*Corresponding authors: Tel/Fax: +86 22 84845242; E-mail: yixl@tjipr.com; liucx@tjipr.com

Received: 26 February 2013;

Accepted: 2 July 2013;

Published online: 15 January 2014;

AJC-14537

\begin{abstract}
Drug-drug interaction is one of the most important preclinical investigation directions. It may have serious impact on drug absorption, distribution and elimination through membrane transporters. Liquid chromatography/Tandem mass spectrometry (LC/MS/MS) could be used to investigate drug-drug interaction in vitro. A sensitive LC/MS/MS method was established for quantification of rosuvastatin in HEK293 and S2 cell lysates. Internal standard (IS) was indapamide. Detection mode was positive electrospray ionization. The lower limit of quantification (LLOQ) was $0.05 \mathrm{ng} / \mathrm{mL}$. The affinity of rosuvastatin with organic anion-transporting polypeptides $1 \mathrm{~B} 1$ and $2 \mathrm{~B} 1$ (OATP1B1 and OATP2B1) was investigated through uptake experiment. All cell samples were precipitated with methanol. Analytes were separated by reversed-phase chromatography and analyzed by Tandem mass spectrometry using $m / z \quad 482.2 / 258.1$ for rosuvastatin and $\mathrm{m} / 2,366.1 / 132.1$ for indapamide. Rosuvastatin uptake was saturable with $\mathrm{Km}$ value of 11.70 and $5.98 \mu \mathrm{M}$ for OATP1B1 and OATP2B1. Rosuvastatin could be used as a good probe for studying membrane transporter activity and drug-drug interaction through LC/MS/MS method.
\end{abstract}

Keywords: LC/MS/MS, Transporter, Rosuvastatin, OATP1B1, OATP2B1.

\section{INTRODUCTION}

Drug transporters are functional proteins located in cytomembranes. Drug absorption, distribution and elimination could be affected by transporters. Drug-drug interaction mediated by transporters could result in serious adverse drug reaction, so it has been recognized as an important preclinical study. The results could be used as crucial parameters for clinical study which would be helpful for improving the success probability of new medicine research and development.

Transporters could be divided into two kinds. One is solute carrier (SLC) transporter and the other is ATP-binding cassette $(\mathrm{ABC})$ transporter. Solute carrier transporters and ABC transporters mainly exist in intestinal epithelia, hepatocytes, kidney proximal tubules and blood-brain barrier ${ }^{1}$. Organic anion-transporting polypeptides (OATPs), organic anion transporters and organic cation transporters are the representatives of SLC transporters. P-Glycoprotein (P-gp), breast cancer resistance protein, bile salt export pump and multidrug resistance proteins are the representatives of $\mathrm{ABC}$ transporters. The affinity between drug and transporters is important for drug absorption, distribution and elimination. Drug-drug interaction mediated by transporters is crucial for studying adverse drug reaction caused by combined medication. Several standard transport substrates have been defined for these transporters including paraaminohippuric acid (PAH), prostaglandin F2 $\alpha$ (PGF2 $\alpha$ ), estrone sulphate and tetraethylammonium (TEA). Traditional method for studying transporters was radioisotope method. Transporter substrates or target drugs were marked with radioisotope. Then through uptake experiment and inhibition test, the affinity relationship and drug-drug interaction could be investigated. Numbers of scientists have tried to establish the non-radio label method for transporter studying in vitro during the last decade, but it has some difficulties because lower limit of quantification of non-radiolabel method may not meet quantification requirement. Recently, fexofenadine was found as a good substrate and probe for OATP1A2 and $\mathrm{P}-\mathrm{gp}$ and LC/MS/MS method was established for the quantification of fexofenadine in cell lysates ${ }^{2}$. Gadoxetate was also found as the substrate of OATP1B1 and a high sensitive LC/MS/MS method was established for its quantification in serum and cell lysates ${ }^{3}$. LC/MS/MS could also be used as a good method for studying drug pharmacodynamics and pharmacokinetics in vitro ${ }^{4}$. 
Although some probes like fexofenadine and gadoxetate have been used for in vitro transporter studying successfully by some scientists. More probes still need to be found to fit different membrane transporters urgently. From large numbers of transporter substrates, we have found another compound rosuvastatin which was also fit for LC/MS/MS analysis. Rosuvastatin is a representative member of statin classes (HMG-CoA reductase inhibitors) used for treating high cholesterol and avoiding cardiovascular disease happening 5 . Rosuvastatin is the substrate of several membrane transporters including OATP1B1, OATP2B1, OATP1B3 and OATP1A2 ${ }^{6}$, $\mathrm{OAT}^{7,8}$, P-gp, BCRP and MRP2 ${ }^{9,10}$. Because rosuvastatin covers quite a few transporters, sensitive LC/MS/MS method for rosuvastatin will be meaningful for in vitro transporter studying strategy. On one hand, non-radio label method could be used for studying drug-drug interaction between rosuvastatin and target drugs. The results could be applied for predicting the affinity of target drugs with transporters. On the other hand, rosuvastatin could be regarded as a good probe for characterizing transporter activity in vitro.

In this paper, a sensitive LC/MS/MS method was applied for identification and quantification of rosuvastatin in HEK293 and $\mathrm{S} 2$ cell lysates. Rosuvastatin uptake experiment mediated by HEK293 OATP1B1 and OATP2B1 cells was done. The function of HEK293 OATP1B1 and OATP2B1 cells was validated according to the positive results of ${ }^{3} \mathrm{H}$-estrone sulphate uptake experiment. Lower limit of quantification was enough for in vitro transporter studying which was validated by the experimental data. It is also emphasize that LC/MS/MS method could also be applied for high throughput screening positive transporter substrates.

\section{EXPERIMENTAL}

Rosuvastatin calcium (purity $>99 \%$ ) was obtained from Beijing Mingjia Chengcheng Pharmaceutical Technology Development Co., Ltd, China (Lot No.100502). Indapamide (purity $>99 \%$ ) was obtained from Tianjin Lisheng Pharmaceutical Co., Ltd., China (Lot No.Y0703003). Methanol and acetonitrile were obtained from Tianjin Concord Reagent Company, China. Water was refined from water purifier (Beijing Zhongsheng Maoyuan Tech. Co. Ltd, China). HEK293 and S2 cells were bought from Cell Center of Chinese Academy of Medical Sciences, Institute of Basic Medical Sciences (Beijing, China). DMEM culture solution, DPBS and fetal Bovine serum were bought from GIBCO Company (Shanghai, China). ${ }^{3} \mathrm{H}$-estrone sulphate was obtained from China Isotope Company (Beijing, China) and specific activity was $1.687 \mathrm{Tbq} / \mathrm{mmol}$. HEK293 OATP1B1 and OATP2B1 cells were given as a gift by Fuji Biomedix Co., Ltd (Japan).

Sample preparation: HEK293 cells were incubated in $\mathrm{CO}_{2}$ incubator (Thermo Scientific) at $37{ }^{\circ} \mathrm{C}$ and $5 \% \mathrm{CO}_{2} . \mathrm{S} 2$ cells were incubated in $\mathrm{CO}_{2}$ incubator at $33{ }^{\circ} \mathrm{C}$ and $5 \% \mathrm{CO}_{2}$. Culture solution was DMEM with $10 \%$ fetal Bovine serum. After passage for at least two times, cell growth status and transporter protein expression were stable. Then HEK293 and $\mathrm{S} 2$ cells were seeded in 24 -well plates. The initiative cell concentration was $2 \times 10^{5}$ per well. After incubating for $40 \mathrm{~h}$, 24-well plates were covered with monolayer cells. After disposing culture solution, washing with $0{ }^{\circ} \mathrm{C}$ DPBS buffer for 3 times and disposing DPBS buffer completely, each well of 24 well plates was added $300 \mu \mathrm{L}$ methanol. After extraction (including cells and methanol), vigorously vortex for $30 \mathrm{~s}$ and centrifugation at $12000 \mathrm{rpm}$ for $5 \mathrm{~min}$, supernatant was separated. Because supernatant contained cell lysates matrix, so it was named as cell lysates methanol as follows.

Rosuvastatin and indapamide (internal standard) stock solutions were prepared in methanol $(0.5 \mathrm{mg} / \mathrm{mL})$, respectively. Internal standard working solution was obtained by diluting internal standard stock solution with mobile phase to get the concentration of $50 \mathrm{ng} / \mathrm{mL}$. HEK 293 and S2 cell lysates were obtained by evaporating cell lysates methanol to dryness at $40^{\circ} \mathrm{C}$ under a gentle stream of nitrogen. HEK293 and S2 cell lysates were spiked with rosuvastatin working solutions to obtain final rosuvastatin concentration of $0.05,0.1,0.3,1,3$, $10,30 \mathrm{ng} / \mathrm{mL}$, containing internal standard at the concentration of $5 \mathrm{ng} / \mathrm{mL}$. In a similar manner, quality control (QC) samples were prepared independently on separate days at the concentration of $0.1 \mathrm{ng} / \mathrm{mL}$ (low), $1 \mathrm{ng} / \mathrm{mL}$ (medium) and $24 \mathrm{ng} / \mathrm{mL}$ (high) respectively.

LC/MS/MS condition: Chromatography column is a Symmetry $\mathrm{C}_{18}(5 \mu \mathrm{m}, 4.6 \times 100 \mathrm{~mm})$. The mobile phase is methanol, acetonitrile and water ( $1 \%$ formic acid) with the ratio of $27: 27: 46$. Total flow rate is $0.4 \mathrm{ml} / \mathrm{min}$. Run time is $8 \mathrm{~min}$ and 4.0-7.5 min is switching over into mass spectrometer. Column temperature is $40^{\circ} \mathrm{C}$. Sample injection temperature is $5^{\circ} \mathrm{C}$ and injection volume is $20 \mu \mathrm{L}$.

Mass spectrometer is Thermo Finnigan TSQ quantum mass spectrometer. Detection mode is positive ion electrospray ionization. Spray voltage is $4800 \mathrm{~V}$. Capillary temperature is $300{ }^{\circ} \mathrm{C}$. Sheath gas is 40 and Auxiliary gas is 14 . Scanning mode is selected reaction monitoring (SRM). The SRM transitions $(\mathrm{m} / \mathrm{z})$ are 482.2/258.1 for rosuvastatin and 366.1/132.1 for indapamide. The collision gas is high purity argon. The collision energy is set at $36 \mathrm{eV}$ for rosuvastatin and $16 \mathrm{eV}$ for internal standard. Data calculation is performed with Xcalibur 1.4SR1 data-processing system.

\section{Bioanalytical method validation}

System suitability: Rosuvastatin and indapamide were ionized at positive ion electrospray ionization mode. CID full scan analysis was run for hydrogenation molecular. After optimization, product ions $(\mathrm{m} / \mathrm{z}, 258.1)$ for rosuvastatin and $(\mathrm{m} / \mathrm{z}$ 132.1) for indapamide were chosen for quantitative analysis detection.

Two standard samples were injected (each sample for 3 times) with LC/MS/MS condition described above. Relative standard deviation (RSD) was calculated for 6 peak area. System suitability was validated for intra-day and inter-day experiment.

Selectivity: To investigate whether endogenous substance would prevent rosuvastatin and IS detection, 6 different blank samples (cell lysates reconstituted with mobile phase) were analyzed to detect potential interference. As contrast, 0.05 $\mathrm{ng} / \mathrm{mL}$ rosuvastatin (LLOQ) was prepared according to sample preparation method and analyzed by LC/MS/MS. Chromatographic peaks of analyte and IS were identified on the basis of their retention times and SRM responses. 
Lower limit of quantification: To determine the LLOQ of our LC/MS/MS method, six replicates of rosuvastatin sample with the concentration of $0.05 \mathrm{ng} / \mathrm{mL}$ were analyzed with LC/MS/MS. The precision should be less than $20 \%$ and the accuracy should be within $20 \%$.

Linearity: To evaluate linearity, seven rosuvastatin samples with concentration ranged from $0.05-30 \mathrm{ng} / \mathrm{mL}$ were prepared and analyzed in duplicate on three consecutive days. Calibration graphs were obtained using the least square method. Linearity was assessed by linear regression analysis with a weighting factor of $1 / \mathrm{x}^{2}$.

Extraction recovery/matrix effect: Cell lysates methanol was used to reconstitute rosuvastatin and then evaporated to dryness at $40{ }^{\circ} \mathrm{C}$ under a gentle stream of nitrogen. Extraction recovery was determined by comparing the raw peak area of rosuvastatin isolated from spiked cell lysates with standard solution at the same concentration. Experiments were performed at three quality control concentration levels, in triplicate.

Matrix effect was determined by using standard sample to reconstitute cell lysates and comparing its raw peak area with standard solution at the same concentration. Experiments were performed at three quality control concentration levels, in triplicate.

Injection carry-over: After the highest concentration sample of calibration curve, blank sample and LLOQ sample were injected to investigate if obvious carry-over existed.

Precision and accuracy: Intra- and inter-day precision and accuracy were assessed from the results of six replicates of low, medium and high quality control samples on three consecutive days.

Stability: The rosuvastatin stability experiment was investigated by comparing the measured concentrations of low, medium and high quality control samples $(n=6)$ with the spiked concentrations. Because transport uptake experiment time was very short and cell samples were precipitated with methanol immediately after washing with DPBS buffer, there was no storage process. So the stability of quality control samples placed in auto-sampler at $4{ }^{\circ} \mathrm{C}$ for $48 \mathrm{~h}$ was investigated to ensure the stability during LC/MS/MS analyzing.

Uptake experiment: HEK293 OATP1B1, OATP2B1 and MOCK cells were incubated and seeded in 24-well plates. After incubating for $40 \mathrm{~h}, 24$-well plates were covered with monolayer OATP1B1, OATP2B1 and MOCK cells. Then DMEM solution was disposed and OATP1B1, OATP2B1 and MOCK cells were incubated in DPBS buffer added $0.5 \mathrm{mM} \mathrm{MgCl} 2$ and $1 \mathrm{mM} \mathrm{CaCl}_{2}$ for $10 \mathrm{~min}$ at $37^{\circ} \mathrm{C}$. For radio labeled estrone sulphate uptake investigation, ${ }^{3} \mathrm{H}$-estrone sulphate $(0.05 \mu \mathrm{M})$ was investigated for 1 min uptake time mediated by OATP1B1, OATP2B1 and MOCK. For non-radio label studying, $10 \mu \mathrm{M}$ rosuvastatin was investigated for 1, 2, 10 and 20 min uptake time firstly. For concentration-dependent studying, rosuvastatin was investigated for $0.5,1,3,10,30 \mu \mathrm{M}$ dosing concentration. Uptake experiments were terminated by $0{ }^{\circ} \mathrm{CDPBS}$ for 3 times. Dosing volume and DPBS wash volume were both $500 \mu \mathrm{L}$.

For radio label experiment, each well of 24 well plates was added $500 \mu \mathrm{L} 0.1 \mathrm{~mol} / \mathrm{L} \mathrm{NaOH}$ after disposing DPBS. After extraction, each sample was added $3 \mathrm{~mL}$ scintillation solution and quantified with Tri-Carb 2910 TR Liquid
Scintillation Analyzer (Perkin Elmer). For non-radiolabel experiment, each well of 24 well plates was added $300 \mu \mathrm{L}$ methanol after disposing DPBS. After extraction (including cells and methanol), vortex (30 s) and centrifugation (12000 rpm for $5 \mathrm{~min}$ ), supernatant was separated. Then the supernatant was evaporated to dryness at $40{ }^{\circ} \mathrm{C}$ under a gentle stream of nitrogen and reconstituted with mobile phase containing IS at the concentration of $5 \mathrm{ng} / \mathrm{mL}$.

Protein quantification of HEK293 OATP1B1, OATP2B1 and MOCK cells was investigated with BCA Protein Assay Kit (Thermo Scientific) to standardize experiment results.

\section{RESULTS AND DISCUSSION}

Mass spectrometry: The condition of LC/MS/MS for rosuvastatin was confirmed by many experiments and the mass spectrum and product spectrum of rosuvastatin and indapamide were shown in Fig. 1. The results showed that rosuvastatin product ions contained 133.00, 217.03, 258.09, 300.10, 314.12, 404.18, 446.18, 482.20, 503.62 and 595.45 at $\mathrm{m} / \mathrm{z}$. Product ion $258.09 \mathrm{~m} / \mathrm{z}$ was selected because of its relative abundance. For indapamide product ion $132.1 \mathrm{~m} / \mathrm{z}$ was selected.

\section{Bioanalytical method validation}

System suitability: The inter-day and intra-day results showed that rosuvastatin RSD ranged from 3.39 to $5.71 \%$ and indapamide RSD ranged from 3.66 to $4.51 \%$. The variability meets the acceptable criterion. So system suitability is good for present LC/MS/MS method.

Selectivity: The results of selectivity investigation were shown in Fig. 2. The retention time was $7 \mathrm{~min}$ for rosuvastatin and $4.8 \mathrm{~min}$ for IS. There is no interference at the retention time of analyte or IS. The results indicate that this method exhibit good selectivity.

Linearity and LLOQ: The calibration curve ranged from 0.05 to $30 \mathrm{ng} / \mathrm{mL}$. Representative calibration curve was shown in Fig. 3. The correlation coefficient $\left(r^{2}\right)$ was over 0.99 for all calibration curves which demonstrated that linearity of this method was good.

The LLOQ was $0.05 \mathrm{ng} / \mathrm{mL}$ for rosuvastatin. The accuracy for six LLOQ samples was $-0.8 \%$. The precision was $10.3 \%$.

Extraction recovery/matrix effect: The average extraction recovery ranged from $90.6-102.5 \%$ for three QC levels. The recovery of IS was $102.5 \%$. The results were shown in Table-1.

The average matrix effect ranged from 96.3 to $99.8 \%$ for three QC levels. The matrix effect of IS was $100.9 \%$. The results were shown in Table-2.

From the results we could see that extraction efficiency was stable and matrix effect was not obvious under these conditions.

Injection carry-over: After injecting the highest concentration sample of calibration curve, blank sample and LLOQ sample were injected to evaluate the carry-over. The results showed that there was no obvious carry-over.

Precision and accuracy: Quality control samples at three concentrations were analyzed in six replicates for determining the accuracy and precision of this method. As shown in Table3 , the intra- and inter-day accuracy ranged from $-6.16 \%$ to $0.35 \%$. The intra-day precision ranged from 3.45 to $5.44 \%$. The inter-day precision ranged from 3.26 to $6.87 \%$. Results 


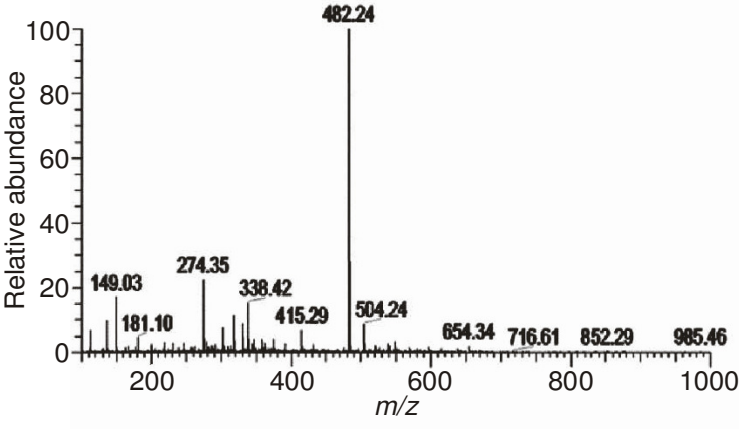

(A)

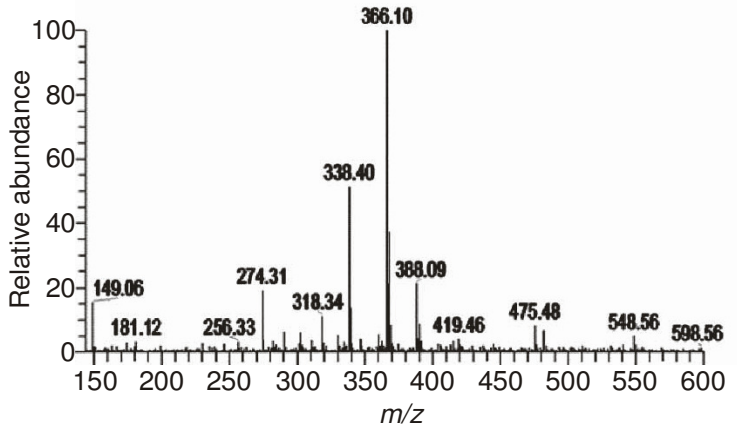

(C)

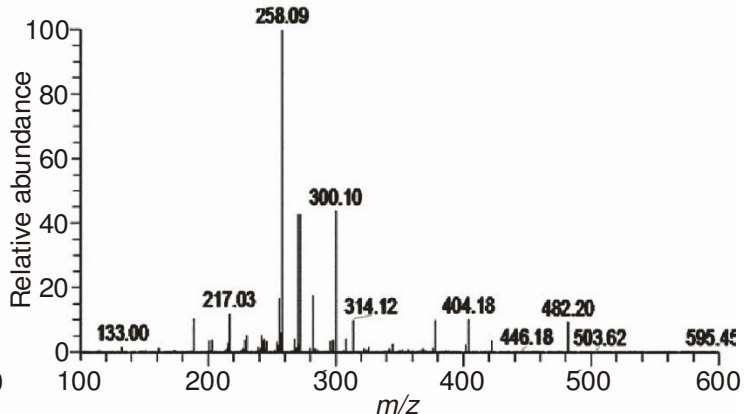

(B)

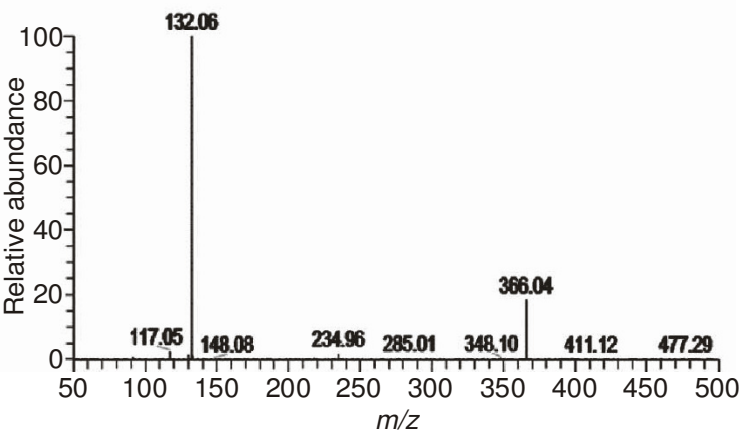

(D)

Fig. 1. Mass spectrum (A) and product spectrum (B) for rosuvastatin; The mass spectrum (C) and product spectrum (D) for indapamide
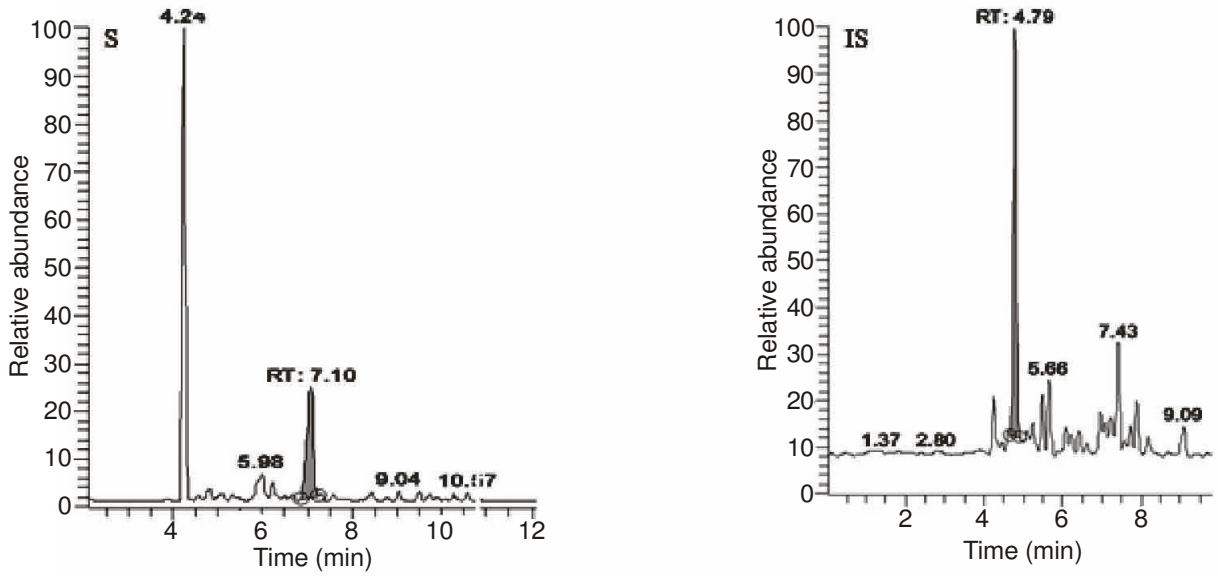

(A)
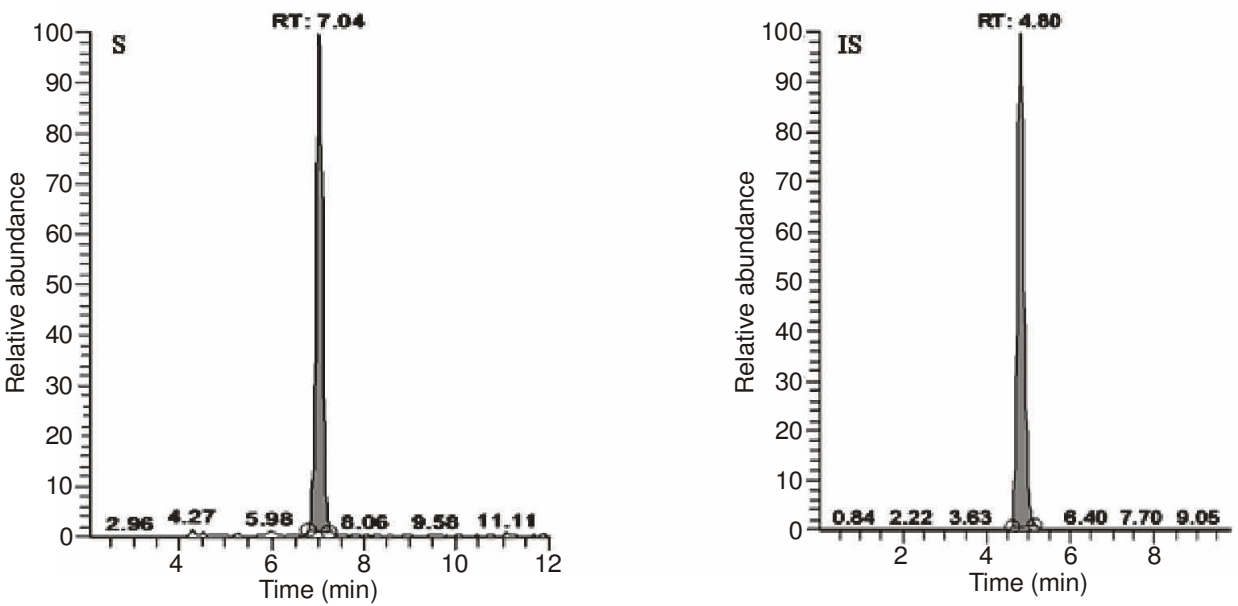

(B)

Fig. 2. MRM chromatograms for blank sample (A) and LLOQ sample (B) 


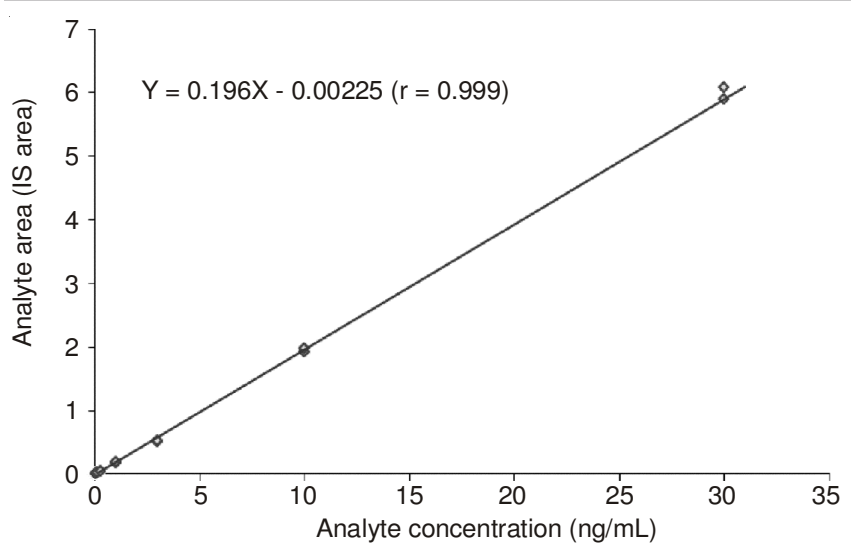

Fig. 3. Representative calibration curve for rosuvastatin quantification

\begin{tabular}{|c|c|c|c|c|}
\hline \multicolumn{5}{|c|}{ TABLE-1 } \\
\hline & \multicolumn{3}{|c|}{ Quality control concentration $(\mathrm{ng} / \mathrm{mL})$} & IS (ng/mL) \\
\hline & 0.1 & 1 & 24 & $5 \mathrm{ng} / \mathrm{mL}$ \\
\hline \multirow{3}{*}{$\begin{array}{c}\text { Recovery } \\
(\%)\end{array}$} & 106.1 & 89.6 & 97.2 & 105.7 \\
\hline & 98.9 & 95.2 & 98.1 & 102.3 \\
\hline & 102.5 & 87.1 & 101.6 & 99.5 \\
\hline Average & 102.5 & 90.6 & 99.0 & 102.5 \\
\hline $\operatorname{RSD}(\%)$ & 3.51 & 4.58 & 2.35 & 3.03 \\
\hline \multicolumn{5}{|c|}{ TABLE-2 } \\
\hline & \multicolumn{3}{|c|}{ Quality control concentration (ng/mL) } & $\mathrm{IS}(\mathrm{ng} / \mathrm{mL})$ \\
\hline & 0.1 & 1.0 & 24 & 5 \\
\hline \multirow{3}{*}{$\begin{array}{c}\text { Matrix } \\
\text { effect (\%) }\end{array}$} & 105.3 & 100.3 & 102.6 & 103.7 \\
\hline & 94.7 & 95.9 & 98.7 & 101.2 \\
\hline & 99.5 & 92.8 & 96.9 & 97.8 \\
\hline Average & 99.8 & 96.3 & 99.4 & 100.9 \\
\hline $\operatorname{RSD}(\%)$ & 5.32 & 3.91 & 2.93 & 2.94 \\
\hline
\end{tabular}

\begin{tabular}{lccc}
\multicolumn{4}{c}{ TABLE-3 } \\
\hline \multirow{2}{*}{ Day } & \multicolumn{3}{c}{ Concentration $(\mathrm{ng} / \mathrm{mL})$} \\
\cline { 2 - 4 } & 0.1 & 1 & 24 \\
\hline RE (\%) & -6.16 & -4.48 & 0.35 \\
Intra-day RSD (\%) & 5.08 & 5.44 & 3.45 \\
Inter-day RSD (\%) & 5.09 & 6.87 & 3.26 \\
\hline
\end{tabular}

were within the acceptable range that indicated our method had a satisfactory accuracy, precision and reproducibility.

Stability: The auto-sampler stability results precision ranged from 3.03 to $11.73 \%$. From the results, we could conclude that the stability of rosuvastatin was good during LC/MS/MS analysis. Present LC/MS/MS method was suitable for analyzing large numbers of samples.

Uptake experiment: Results of MOCK cells uptake experiments were regarded as the negative control. From Fig. 4, we could conclude that the function of HEK293 OATP1B1 and OATP2B1 cells was good. Time dependent investigation (Fig. 5) results showed that incubation time 2 min was the most suitable for concentration dependent investigation (Fig. 6) in consideration of significant difference and experimental efficiency. Michaelis $K_{m}$ and $V_{\max }$ were calculated with linear regression. The values of $\mathrm{K}_{\mathrm{m}}$ and $\mathrm{V}_{\max }$ were $11.70 \mu \mathrm{M}$ and $54.27 \mathrm{pmol} / \mathrm{min} / \mathrm{mg}$ protein for OATP1B1. The values of $\mathrm{K}_{\mathrm{m}}$ and $\mathrm{V}_{\max }$ were $5.98 \mu \mathrm{M}$ and $19.56 \mathrm{pmol} / \mathrm{min} / \mathrm{mg}$ protein for OATP2B1. High affinity of rosuvastatin with OATP1B1 and OATP2B1 transporter protein was proved. All experiment

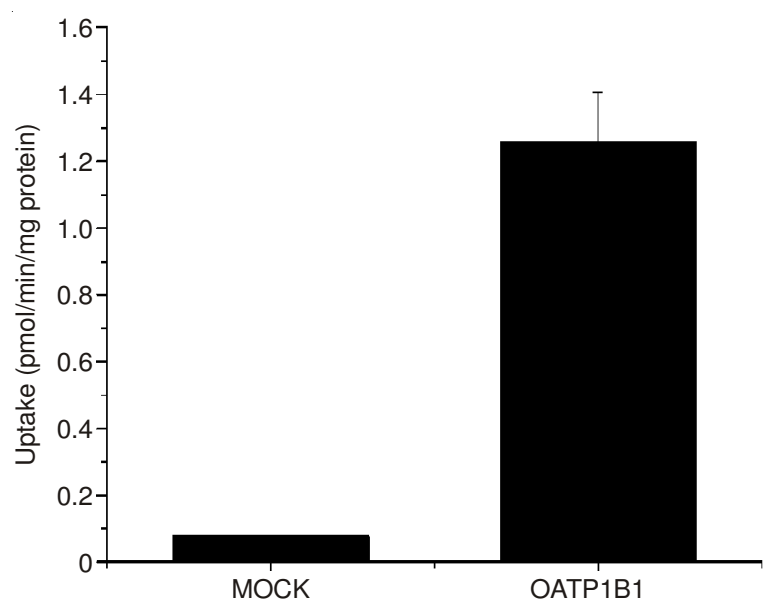

(A)

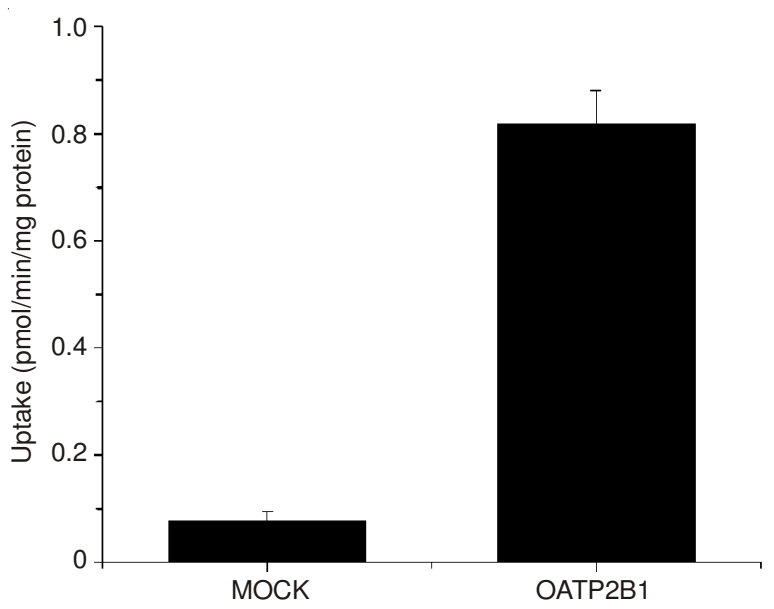

(B)

Fig. 4. (A) Cell function confirmation of OATP1B1 transfected HEK293 cells; (B) Cell function confirmation of OATP2B1 transfected HEK293 cells

results were standardized by protein content of corresponding cells (protein standard line $r^{2}>0.99$ ).

Every year, a large number of new chemical entities (NCEs) are discovered and drug metabolism and pharmacokinetics (DMPK) of these new chemical entities need to be investigated. High-throughput methods need to be built urgently. LC/MS/MS is a representative high-throughput detection method which can be used for sample analysis in vitro. LC/ MS/MS successfully applied to P-glycoprotein inhibition assay in vitro was reported by Smalley et al. ${ }^{11}$.

In this paper, LC/MS/MS was used for rosuvastatin quantification. The reason for chosing rosuvastatin was because rosuvastatin was proved to be the substrate of quite a few membrane transporters during the last decade. So high-throughput detection method of rosuvastatin was meaningful for investigating the function of these transporters and studying drugdrug interaction between rosuvastatin and other compounds.

Until now, several papers have reported the quantification method of rosuvastatin. High performance liquid chromatography with ultraviolet detection (HPLC-UV) ${ }^{12,13}$ and LC/MS/ MS techniques ${ }^{14-17}$ were used for rosuvastatin quantification. And we established a sensitive LC/MS/MS method for the quantification of rosuvastatin in cell lysates for the first time. The LLOQ was good enough $(0.05 \mathrm{ng} / \mathrm{mL})$ and suitable 


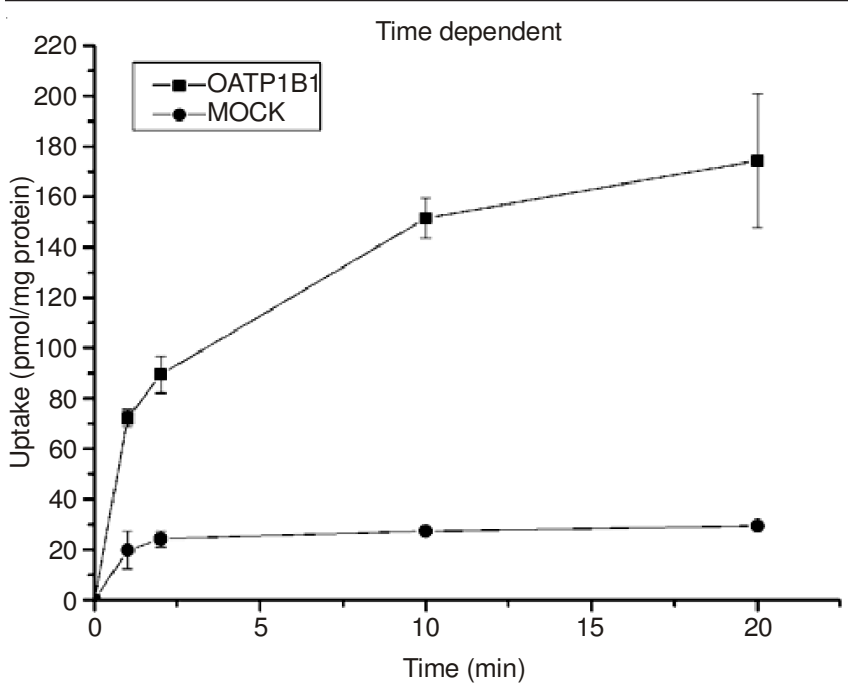

(A)

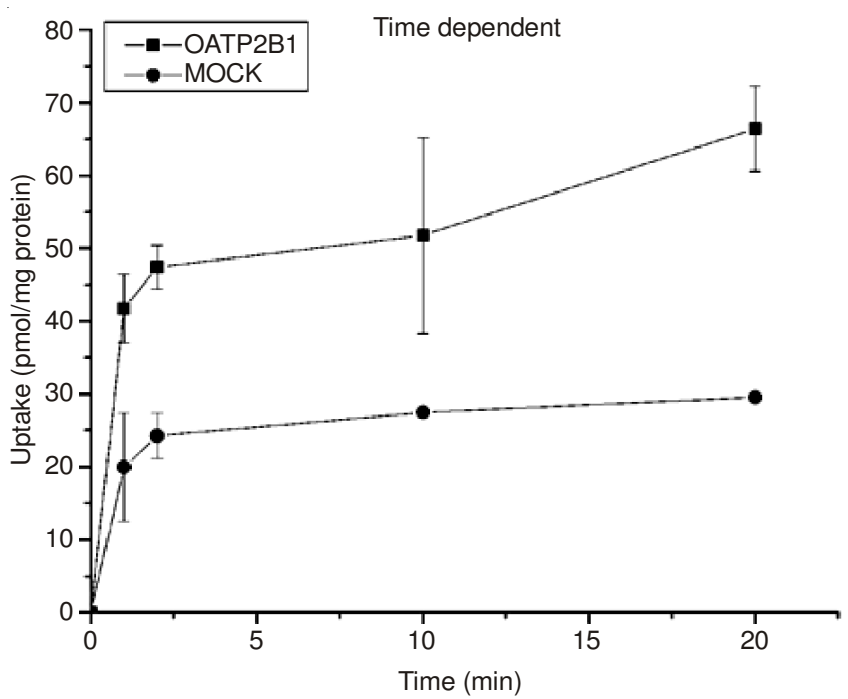

(B)

Fig. 5. (A) Time dependent line of rosuvastatin uptake mediated by OATP1B1; (B) Time dependent line of rosuvastatin uptake mediated by OATP2B1

for analyzing uptake experiment samples which was validated by our results.

For uptake experiment, the function of HEK293 OATP1B1 and OATP2B1 cells was validated and the high affinity of rosuvastatin with OATP1B1 and OATP2B1 was proved. Several papers have reported the affinity investigation by radio labeled rosuvastatin uptake experiment ${ }^{6,18}$. Our non-radiolabel method was used for determining $\mathrm{K}_{\mathrm{m}}$ values of rosuvastatin mediated by OATP1B1 and OATP2B1 for the first time. There is almost no difference between our results and radiolabel method results which means that LC/MS/MS could also be used for transporter studying in vitro with high accuracy.

Several papers have reported that drug-drug interaction happens not only between synthetic drugs, but also between synthetic drug and herbal medicine. Baicalin (a herbal medicine) was found to be able to decrease the plasma concentration of rosuvastatin mediated by OATP1B $1^{19}$. So drug-drug interaction between herbal medicine and synthetic drugs which may lead to treatment failure must be pay attention ${ }^{20}$. And present LC/ MS/MS method could also be used for this purpose.

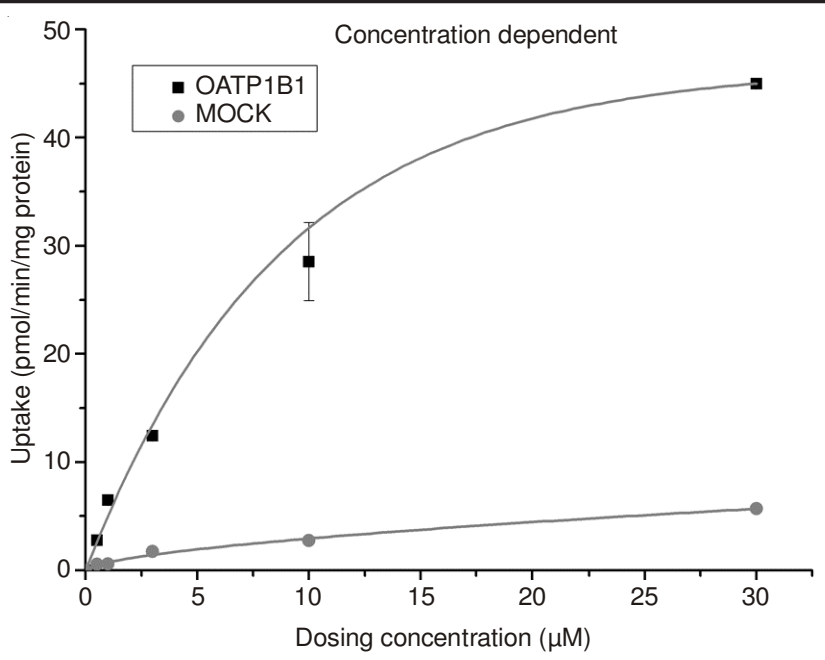

(A)

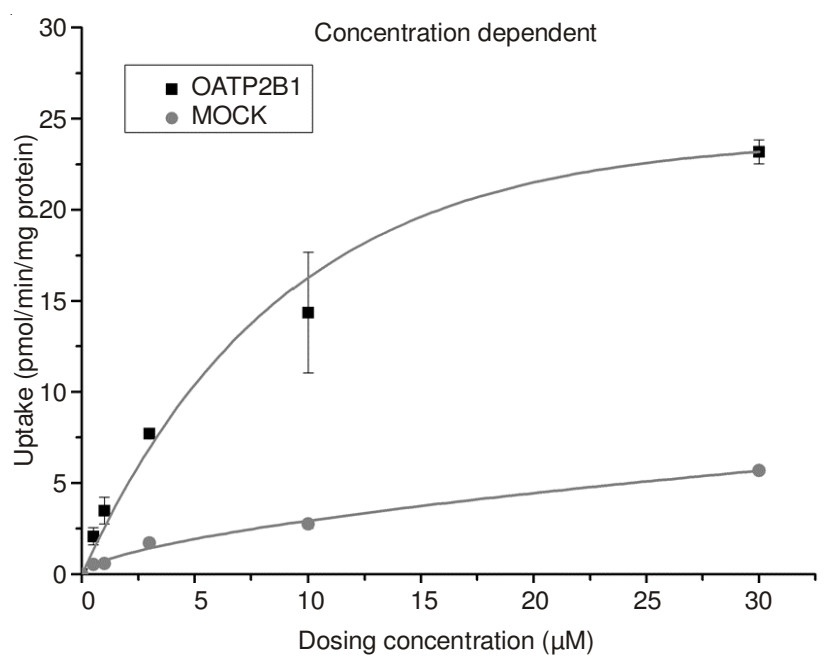

(B)

Fig. 6. (A) Concentration dependent line of rosuvastatin uptake mediated by OATP1B1 with 2 min absorption time; (B) concentration dependent line of rosuvastatin uptake mediated by OATP2B1 with 2 min absorption time

\section{Conclusion}

A rapid, sensitive with high specificity LC/MS/MS method was established in this work for rosuvastatin quantification in cell lysates. This non-radio label method demonstrated similar sensitivity, linearity and reproducibility compared with radio label method. The affinity of rosuvastatin with OATP1B1 and OATP2B1 was proved by our results and the $\mathrm{K}_{\mathrm{m}}$ values were detected. Our LC/MS/MS method could be used widely in the future not only for drug-drug interaction studying but also for validating transporter activity and predicting and screening new substrates. Although rosuvastatin is such a good probe for quite a few transporters, more probes need to be found for the development of drug evaluation in vitro in the future.

\section{ACKNOWLEDGEMENTS}

This study was supported by National 973 Project Foundation of China (2010CB735602, 2012CB72400-2) and National Significant New Drug Creation Project Foundation of China (2011ZX09102-009-002, 2012ZX09304-002). 


\section{REFERENCES}

1. K.M. Giacomini, S.M. Huang, D.J. Tweedie, L.Z. Benet, K.L.R Brouwer, X. Chu, A. Dahlin, R. Evers, V. Fischer, K.M. Hillgren, K.A. Hoffmaster, T. Ishikawa, D. Keppler, R.B. Kim, C.A. Lee, M. Niemi, J.W. Polli, Y. Sugiyama, P.W. Swaan, J.A. Ware, S.H. Wright, S. Wah Yee, M.J. Zamek-Gliszczynski and L. Zhang, Nat. Rev. Drug. Discov., 9, 215 (2010).

2. C.A. Flynn, Y. Alnouti and G.A. Reed, Rapid Commun. Mass Spectrom., 25, 236 (2011).

3. J. Jia, M. Keiser, A. Nassif, W. Siegmundand and S. Oswald, J. Chromatogr. B; Analyt. Technol. Biomed. Life Sci, 891, 20 (2012).

4. I. Chu and A.A. Nomeir, Curr. Drug. Metab., 7, 467 (2006).

5. G.N. Levine, J.F. Keaney Jr. and J.A. Vita, N. Engl. J. Med., 332, 512 (1995)

6. R.H. Ho, R.G. Tirona, B.F. Leake, H. Glaeser, W. Lee, C.J. Lemke, Y. Wang and R.B. Kim, Gastroenterology, 130, 1793 (2006)

7. A.S. Windass, S. Lowes, Y. Wang and C.D. Brown, J. Pharmacol. Exp. Ther, 322, 1221 (2007).

8. T. Watanabe, H. Kusuhara, T. Watanabe, Y. Debori, K. Maeda, T. Kondo, H. Nakayama, S. Horita, B.W. Ogilvie, A. Parkinson, Z. Hu and Y Sugiyama, Drug. Metab. Dispos., 39, 1031 (2011).

9. S. Kitamura, K. Maeda, Y. Wang and Y. Sugiyama, Drug. Metab. Dispos., 36, 2014 (2008).
10. J. Li, D.A. Volpe, Y. Wang, W. Zhang, C. Bode, A. Owen and I.J. Hidalgo, Drug. Metab. Dispos., 39, 1196 (2011).

11. J. Smalley, A.M. Marino, B. Xin, T. Olah and P.V. Balimane, J. Chromatogr. B, 854, 260 (2007).

12. T.R. Kumar, N.R. Shitut, P.K. Kumar, M.C.A. Vinu, V.V.P. Kumar, R. Mullangi and N.R. Srinivas, Biomed. Chromatogr., 20, 881 (2006).

13. S. Vittal, N.R. Shitut, T.R. Kumar, M.C.A. Vinu, R. Mullangi and N.R. Srinivas, Biomed. Chromatogr., 20, 1252 (2006).

14. C. Hull, A. Penman, C. Smith and P. Martin, J. Chromatogr. B; Analyt. Technol. Biomed. Life Sci., 772, 219 (2002).

15. K.A. Oudhoff, T. Sangster, E. Thomas and I.D. Wilson, J. Chromatogr. B; Analyt. Technol. Biomed. Life Sci., 832, 191 (2006).

16. J. Gao, D. Zhong, X. Duan and X. Chen, J. Chromatogr. B; Analyt. Technol. Biomed. Life Sci., 856, 35 (2007).

17. J.S. Macwan, I.A. Ionita and F. Akhlaghi, Anal. Bioanal. Chem., 402, 1217 (2012).

18. S.G. Simonson, A. Raza, P.D. Martin, P.D. Mitchell, J.A. Jarcho, C.D. Brown, A.S. Windass and D.W. Schneck, Clin. Pharmacol. Ther, 76, 167 (2004).

19. L. Fan, W. Zhang, D. Guo, Z.R. Tan, P. Xu, Q. Li, Y.Z. Liu, L. Zhang, T.Y. He, D.L. Hu, D. Wang and H.H. Zhou, Clin. Pharmacol. Ther, 83, 471 (2008).

20. C.X. Liu, X.L. Yi, D.Y. Si, X.F. Xiao, X. He and Y.Z. Li, Curr. Drug. Metab., 12, 835 (2011). 